\title{
A PERSECUÇÃo PENAL SUSTENTÁVEL DOS CRIMES DE PERIGO ABSTRATO NOS DELITOS AMBIENTAIS ${ }^{1}$
}

\author{
Andressa Kelle Custódio SILVA ${ }^{1}$
}

Magno Federici GOMES ${ }^{2}$

\begin{abstract}
${ }^{1}$ Mestranda em Direito Constitucional Ambiental - Escola Superior Dom Helder Câmara, graduada Direito - Faculdade Vale do Gorutuba - FAVAG (2012). Pós graduação em Direito Processual - Faculdade Vale do Gorutuba. Está cursando pós graduação em Direito Previdenciário - Universidade Norte do Paraná - UNOPAR. Atualmente é professora especialista da FAVENORTE e professora especialista do Centro de Educação Virtual Ltda polo de apoio da Universidade Norte do Paraná, advogada do Sindicato dos Servidores Públicos Municipais de Janaúba - SINDJANA e Procuradora da Prefeitura Municipal de Matias Cardoso - MG. Tem experiência na área de Direito, com ênfase em Direito Público. kelleandressa1 @ hotmail.com

${ }^{2}$ Pós-doutor em Direito Público e Educação pela Universidade Nova de Lisboa-Portugal. Pós-doutor em Direito Civil e Processual Civil, Doutor em Direito e Mestre em Direito Processual, pela Universidad de Deusto-Espanha. Mestre em Educação pela PUC Minas. Professor do Mestrado Acadêmico em Direito Ambiental e Sustentabilidade na Escola Superior Dom Helder Câmara. Professor Adjunto da PUC Minas e Professor Titular licenciado da Faculdade de Direito Arnaldo Janssen. Advogado Sócio do Escritório Raffaele \& Federici Advocacia Associada. Integrante dos grupos de pesquisa: Regulação Ambiental da Atividade Econômica Sustentável (REGA)/CNPQ-BRA, Centro de Investigação \& Desenvolvimento sobre Direito e Sociedade (CEDIS)/FCT-PT e Núcleo de Estudos sobre Gestão de Políticas Públicas (NEGESP)/CNPQ-BRA. federici@pucminas.br
\end{abstract}

Recebido em: 16/10/2016 - Aprovado em: 20/08/2017 - Disponibilizado em: 30/12/2017

\section{RESUMO}

Este estudo tem por finalidade analisar a criminalização das condutas que exaurem o chamado crime de perigo abstrato, representando na verdade uma possível ofensa a um bem jurídico tutelado, sendo essa punição através da tutela ambiental como a única maneira de alcançar um futuro sustentável. O problema se vincula as ações do Estado na punição dos crimes de perigo abstrato em infrações penais ambientais. A metodologia foi a teórico documental, com técnica dedutiva e pesquisa bibliográfica. Os crimes de perigo concreto, em sede de tutela do meio ambiente, são, na prática, de difícil aplicação em face da dificuldade de se provar a ocorrência do perigo.

Palavras-chave: Criminalização; Perigo; Meio ambiente; Sustentabilidade.

\section{SUSTAINABLE PUNISHMENT IN ABSTRACT DANGER CRIMES IN ENVIRONMENTAL MATTERS}

\begin{abstract}
This study aims to analyze the criminalization of conduct that deplete the so-called abstract danger of crime, actually represented a possible danger of offending a tutored legal right, and this punishment through environmental protection the only way to achieve a sustainable future. As a research problem was defined: "What state actions in the cohesion of abstract danger of crimes in environmental criminal offenses"? The methodology was theoretical documentary through deductive method and literature developed based on material already prepared as scientific books and paper, jurisprudences, etc. The crimes of real danger, in environmental protection headquarters, are in practice difficult to enforce, given the difficulty of proving the danger occurrence.
\end{abstract}

Keywords: Criminalization; Danger; Environment; Sustainability.

\footnotetext{
${ }^{1}$ Trabalho financiado pelo Edital $n^{\circ}$ 05/2016 (Projeto $n^{\circ}$ FIP 2016/11173-S2) do FIP/PUC MINAS, resultante dos Grupos de Pesquisas (CNPQ): Regulação Ambiental da Atividade Econômica Sustentável (REGA), NEGESP e CEDIS (FCT-PT). 


\section{INTRODUÇÃO}

O direito penal ambiental se utiliza dos modelos de perigo abstrato para proteger os bens jurídicos, sendo notório a todos que o meio ambiente é um bem frequentemente sujeito a ataques e merece ser preservado principalmente com o desenvolvimento tecnológico acelerado que convive com a sociedade contemporânea.

A punição desses crimes de perigo abstrato, sem resultado naturalístico, representa o único mecanismo de efetividade para empreender uma séria e real tutela do meio ambiente.

Para configuração do crime de perigo abstrato basta a prática da conduta descrita no tipo penal, mesmo que não se evidencie algum perigo para o bem jurídico tutelado, sendo suficiente a simples verificação de uma atividade perigosa.

A doutrina majoritária entende que o perigo abstrato também conhecido como crime presumido e inserido na conduta do agente. Não precisa ser provado uma vez que para a configuração da infração penal basta a prática da ação ou omissão que a lei pressupõe perigosa.

Como direito fundamental expresso no texto constitucional todos têm direito ao meio ambiente ecologicamente equilibrado, bem de uso comum do povo e essencial à sadia qualidade de vida, impondo-se ao Poder Público e a coletividade o dever de defendê-lo e preservá-lo para as presentes e futuras gerações.
Propõe-se como problema da pesquisa: "como age o Estado na punibilidade dos crimes de perigo abstrato nas infrações penais ambientais"?

Nessa perspectiva, o objetivo do presente estudo consiste em analisar a criminalização das condutas que exaurem o chamado crime de perigo abstrato.

A metodologia foi a teórico documental e dedutiva, com técnica bibliográfica. Assim, foram consultadas doutrinas, revistas, jurisprudência, artigos e livros que abordam o tema proposto. O método dedutivo origina-se da aplicação de princípios gerais a casos específicos. $\mathrm{Na}$ dedução, o raciocínio parte de uma premissa geral para o particular. De um princípio geral, chega-se ao particular.

\section{PODER DE POLÍCIA NAS INFRAÇÕES AMBIENTAIS}

Segundo Mello (2009), a expressão poder de polícia tomada em seu sentido restrito relaciona-se unicamente com as intervenções quer gerais ou abstratas quer concretas ou específicas do Poder Executivo, destinadas a alcançar o fim de prevenir e conter o desenvolvimento de atividades particulares contrastantes com os interesses sociais $^{2}$.

Para Di Pietro (2004, p. 94), o poder de polícia é a atividade do Estado consistente

\footnotetext{
${ }^{2}$ Para analisar a ideia de desenvolvimento econômico em contraposição ao desenvolvimento sustentável e estudar um caso concreto, ver: BIZAWU; GOMES, 2016, p. 18-21.
} 
em limitar o exercícios dos direitos individuais em benefício do interesse público.

Nota-se que o poder de polícia visa a restrição e o uso e gozo de certos bens, direitos individuais e atividades em benefício da coletividade. Assim, o poder de polícia deve ser amplamente aplicado ao Direito ambiental, que tem como premissa balizar o meio ambiente, que é um bem coletivo para toda a humanidade.

De acordo com Milaré (2011, p. 1132), poder de polícia ambiental é a ação da Administração Pública que restringe ou regula interesse de liberdade ou direito, disciplina a execução de ação ou a abstinência de evento em função de interesse público referente ao bem-estar da população, a manutenção dos ecossistemas, à regulação do mercado e da produção, ao exercício da ação econômica ou de demais ações que dependam consentimento e da produção, ao exercício da ação econômica ou de demais ações que dependam do consentimento, licença/concessão ou autorização do Poder Público de quais ações proceder à agressão à natureza ou poluição.

A polícia ambiental, utilizando de seu poder, deve restringir em alguns casos o uso e o gozo dos recursos naturais, pois assim poderá reduzir o impacto causado por danos ambientais.

\section{OS CRIMES DE PERIGO E A TUTELA DO MEIO AMBIENTE}

Em se tratando da tutela do meio ambiente, os crimes de perigo estão em sincronia com os princípios da prevenção e da precaução, pois estes tutelam o bem jurídico antes de sua efetiva lesão.

Conforme pode-se verificar em Sirvinskas (2008, p. 591) no crimes ambientais, os bens jurídicos protegidos aproximam-se mais do "perigo" do que do "dano". Isso permite realizar um prevenção e ao mesmo tempo um repressão, assim ocorre uma antecipação da proteção penal, reprimindo-se as condutas preparatórias.

Conforme pode ser observado em Fiorillo (2014, p. 89) a responsabilidade ambiental instituída no $\S 3^{\circ}$, do art. 225 da Constituição da República de 1988 (CR/88), exprime-se pelo princípio da prevenção e da precaução, pois este, obriga antes de tudo, que sejam adotadas medidas de prevenção do dano, não se esperando um momento posterior, quando da ocorrência do dano.

Nota-se que para todos os autores o princípio busca a prevenção do dano, o que sempre levará a uma antecipação da ocorrência do dano.

\section{CRIME DE PERIGO CONCRETO}

Nos crimes de perigo concreto, o perigo constitui um elemento do tipo que o perigo integra o tipo como elemento normativo, conforme preceitua Prado (2006, p.241): 
Na visão de Fragoso (1985, p. 173) o crime de perigo concreto ocorre quando a realização da conduta típica traz consigo real probabilidade de dano, de cuja verificação depende a existência do crime. Neste tipo de delito, o perigo é elemento normativo do tipo, integrando a conduta, de forma que há que ser demonstrada, no caso concreto, a sua ocorrência para o fim de se aferir a consumação do crime.

Vários artigos de lei podem ser exemplificados no Código Penal (CP), que correspondem a crime de perigo concreto, conforme pode-se verificar nos arts. 130 Expor alguém, por meio de relações sexuais ou qualquer ato libidinoso, a contagio de moléstia venérea, de que sabe ou deve saber que está contaminado. Já no art. 132 - Expor a vida ou a saúde de outrem a perigo direito e iminente. No art. 250 - causar incêndio, expondo a perigo a vida, a integridade física ou o patrimônio de outrem todos do Código penal (BRASIL, 1940).

Ainda em outras leis, pode-se perceber crimes de dano concreto como o art. 70 da Lei 8.078/90, dispõe que empregar na reparação de produtos, peça ou componentes de reposição usados, sem autorização do consumidor.

Quanto aos delitos de perigo concreto na proteção do bem jurídico ambiental vários são os exemplos que podem ser citados, como os arts. 42, 60 e 61 da Lei 9.605/98 (BRASIL, 1998).
Art. 42. Fabricar, vender, transportar ou soltar balões que possam provocar incêndios nas florestas e demais formas de vegetação, em áreas urbanas ou qualquer tipo de assentamento humano.

Art. $60 . \quad$ Construir, reformar, ampliar, instalar ou fazer funcionar, em qualquer parte do território nacional, estabelecimentos, obras ou serviços potencialmente poluidores, sem licença ou autorização dos órgãos ambientais competentes, ou contrariando as normas legais e regulamentares pertinentes.

Art. 61. Disseminar doença ou praga ou espécies que possam causar dano à agricultura, à pecuária, à fauna, à flora ou aos ecossistemas (BRASIL, 1998, p. 19).

Para Jesus (2007, p. 255), o perigo concreto é o que precisa ser provado no caso, não é presumido, mas, ao contrário, precisa ser investigado e comprovado.

Como pode-se perceber que no crime de perigo concreto, o perigo precisa ser comprovado para assim ocorrer a tipificação do crime.

\section{CRIMES DE PERIGO ABASTRATO NA TUTELA DO MEIO AMBIENTE}

O direito penal prever vários espécies de delitos a melhor saída foi criar ramificações, o conceito de crime passou a ter diversas classificações como crime dolosos, culposos, preterdolosos, comissivos ou omissivos, dentre essas classificações está a "quanto ao resultado" e dentro dela está 
"quanto ao resultado jurídico ou normativo" é nesta que se pode encontrar os crimes de perigo.

O resultado jurídico ou normativo pode ser entendido como a lesão ou ameaça de lesão quem um bem jurídico pode sofrer caso ocorra alguma conduta contra esse bem. Ao lado dos crimes de perigo estão os crimes de dano que é aquele para cuja consumação é necessário a superveniência da lesão efetiva do bem jurídico (BITTENCOURT, 2008, p. 213).

O crime de perigo pode ser dividido em duas categorias, sendo elas as de crimes de perigo concreto ou real e de crimes de perigo abstrato ou presumido.

Sendo os crimes de perigo concreto ou real aqueles cujo risco deve ser demonstrado, o bem jurídico protegido por lei deve está na eminência de sofrer um dano ao passo que o crime de perigo abstrato ou presumido não necessitam que a conduta praticada produza um perigo real, se a conduta demonstrar que pode causar um dano a sociedade, ela será considerada presumidamente perigosa (MIRABETE, 2008, p. 125).

A criminalização do perigo, em matéria de Direito Penal Ambiental reflete a aplicação do princípio da prevenção e da precaução, na medida em que, ao antecipar uma punição de uma suposta conduta potencialmente danosa ao bem jurídico tutelado, dispensa a produção do resultado.
Em comparação ao crime de perigo abstrato os crime de perigo concreto, na tutela do meio ambiente, são, na prática, de difícil aplicação, em face da dificuldade de se provar a ocorrência do perigo.

\section{CONSIDERAÇÕES FINAIS}

Nota-se o direito ambiental como um direito fundamental previsto no texto constitucional. Os recursos naturais são um bem de uso comum do povo, razão pela qual a responsabilidade por sua preservação, além de ser um dever do Estado, é também de toda a coletividade. Adicionou-se às dimensões econômica, social e ambiental, os pilares espacial, jurídico político e ético cultural ao desenvolvimento sustentável.

Por tal motivo, observa-se a urgência da atuação do direito penal ambiental como forma de reduzir os prejuízos e proteger o meio ambiente ecologicamente equilibrado, seja pela punição dos crimes de perigo abstrato ou presumido que representa uma antecipação do dano, evitando na maioria das vezes a finalização de uma conduta sem que ocorra a consumação.

Percebe-se que o Estado, nos crimes de perigo abstrato, atenta para o princípio da prevenção e da precaução porque tipifica as condutas no simples descumprimento da norma imposta pelo legislador, atuando mais facilmente na prevenção do risco que oferecem as condutas que infringem tais normas. 
Por ser o perigo presumido pelo simples descumprimento dos regulamentos impostos pela norma, o meio ambiente é um bem jurídico difuso, antes visto como um recurso inesgotável e que hoje é fonte de preocupação e exige tutela preventiva na sua proteção.

\section{REFERÊNCIAS}

BITTENCOURT, Cezar Roberto. Tratado de direito penal. 12. ed. São Paulo: Saraiva, 2008.

BIZAWU, Kiwonghi; GOMES, Magno Federici. Oil exploitation at Virunga park as a threat to the environment and to endangered animal species. Veredas do Direito, Belo Horizonte, v. 13, n. 27, p. 11-29, set./dez. 2016. Disponível em:

<http://www.domhelder.edu.br/revista/index. php/veredas/article/view/897>. Acesso em: 22 jun. 2017.

BRASIL. Constituição (1988). Constituição da República Federativa do Brasil. Brasília, DF: Senado Federal. Centro Gráfico, 1988. 292 p.

BRASIL. Decreto-Lei 2.848, de 07 dez. 1940. Código Penal. Diário Oficial da União, Brasília, 31 dez. 1940. Disponível em: < http://www.planalto.gov.br/ccivil_03/decretolei/Del2848compilado.htm>. Acesso em: 14 out. 2016.

BRASIL. Lei 8.078, de 11 set. 1990. Dispõe sobre a proteção do consumidor e dá outras providências. Diário Oficial da União, Brasília, 12 set. 1990 (retificado em 10 jan. 2007). Disponível em:

<http://www.planalto.gov.br/ccivil_03/leis/L8 078.htm>. Acesso em: 14 out. 2016. meio ambiente, e dá outras providências. Diário Oficial da União, Brasília, 13 fev. 1998 (retificado em 17 fev. 1998). Disponível em: <

http://www.planalto.gov.br/ccivil_03/leis/L96 05.htm>. Acesso em: 14 out. 2016.

DI PIETRO, Maria Sylvia Zanella. Direito administrativo. 17. ed. São Paulo. Atlas, 2004.

FIORILLO, Celso A. Pacheco. Curso de direito ambiental brasileiro. 15. ed. São Paulo, Saraiva, 2014.

FRAGOSO, Heleno Claudio. Lições de direito penal. 9. ed. Rio de Janeiro, Forense, 1985.

JESUS, Damásio Evangelista de. Direito penal. 20. ed. São Paulo: Saraiva, 2007. vol. 1.

MELLO, Celso Antonio Bandeira de. Curso de direito administrativo. 26. ed. São Paulo. Malheiros. 2009.

MILARÉ, Édis. Direito do ambiente: a gestão ambiental em foco: doutrina - prática jurisprudência - glossário. 7. ed. São Paulo: Revista dos Tribunais, 2011.

MIRABETE, Julio Fabbrini. Manual de direito penal parte geral: arts. 1 a 120. 25 . ed. São Paulo: Atlas, 2008.

PRADO, Luiz Regis. Curso de direito penal brasileiro. São Paulo: Revista dos Tribunais, 2006.

SIRVINSKAS, Luís Paulo. Manual de direito ambiental. 6. ed. São Paulo: Saraiva, 2008.

BRASIL. Lei 9.605, de 12 fev. 1998. Dispõe sobre as sanções penais e administrativas derivadas de condutas e atividades lesivas ao 